\title{
Letters
}

Website: www.bmj.com

Email: letters@bmj.com

\section{Acute otitis media}

Norwegian consensus is that only children with recurrent episodes of otitis media need antibiotics

EDITOR-O'Neill's review of the management of acute otitis media from Clinical Evidence was interesting. Straand et al showed that $64 \%$ of children aged $0-12$ years with acute otitis media in a Norwegian county received antibiotic treatment, ${ }^{2}$ but in a study from an accident and emergency department in Tromsø 91\% of the children with acute otitis media received antibiotics. ${ }^{3}$ This shows the conflict between day to day practice and clinical guidelines that recommend no standard antibiotic treatment for acute otitis media.

O'Neill also addresses the question whether children with recurrent otitis media benefit from antibiotic treatment. The latest Norwegian consensus recommends identifying children who should have antibiotic treatment every time they have otitis media. ${ }^{4}$ These children have had three or more episodes of acute otitis media during the previous six months or four or more episodes during the previous year. Before the age of 2 years $40 \%$ of all children will have an episode of acute otitis media, and 4\% will

\section{Advice to authors}

We prefer to receive all responses electronically, sent either directly to our website or to the editorial office as email or on a disk. Processing your letter will be delayed unless it arrives in an electronic form.

We are now posting all direct submissions to our website within 24 hours of receipt and our intention is to post all other electronic submissions there as well. All responses will be eligible for publication in the paper journal.

Responses should be under 400 words and relate to articles published in the preceding month. They should include $\leqslant 5$ references, in the Vancouver style, including one to the BMJ article to which they relate. We welcome illustrations.

Please supply each author's current appointment and full address, and a phone or fax number or email address for the corresponding author. We ask authors to declare any competing interest. Please send a stamped addressed envelope if you would like to know whether your letter has been accepted or rejected.

Letters will be edited and may be shortened.

www.bmj.com

letters@bmj.com have recurrent episodes. Several studies have been performed to explain why these children are prone to ear infections. Risk factors include a genetic disposition, the age of the first ear infection, and male sex. ${ }^{4}$ Concentrations of antibody against pneumococcus capsule antigens $6 \mathrm{~A}, 14$, and $19 \mathrm{~F}$ are low, and children with recurrent infections are hypothesised to have delayed production of specific immunoglobulins, being unable to increase their own production until the age of $6 .{ }^{4}$

These factors are reasons for giving children with recurrent episodes antibiotic prophylaxis as an alternative to surgical treatment. In a meta-analysis of 958 children one in nine showed improvement after antibiotic treatment. ${ }^{1}$ In a small Swedish study intermittent antibiotic treatment with penicillin $\mathrm{V}$ for 10 days was given every time the child had an upper respiratory infection. This resulted in a 50\% reduction in acute otitis media in the group that received antibiotic prophylaxis.

This shows why finding children with recurrent episodes of acute otitis media is an important issue in general practice. Studies are needed to identify how substantial the benefit from antibiotics is in this particular group. The most important issue, however, is to reduce the overuse of antibiotics in the children who will not have recurrent episodes and will therefore recover just as well without antibiotics.

Morten Lindbaek associate professor

Department of General Practice, University of Oslo, PO Box 1130, N-0317 Oslo, Norway morlind@vestfoldnett.no

1 O'Neill. Clinical evidence: acute otitis media. $B M /$ 1999;319:833-5. (25 September.)

2 Straand J, Rokstad KS, Heggedal U. Drug prescribing for children in general practice. A report from the Møre and Romsdal prescription study. Acta Paediatr 1998;87:218-24.

3 Myrbakk T, Giæver A, Olsvik Ø, Flægstad T. Antibiotic treatment of acute otitis media in children. Tidsskr Nor Laegeforen 1999; 119: 2649-52.

4 Kværner KJ, Mair IWS. Acute and recurrent acute otitis media: guidelines, treatment and prophylaxis. Tidsskr Nor Laegeforen 1997;117:4096-8.

5 Prellner K, Fogle-Hansson M, Jørgensen F, Kalm O, Kamme C. Prevention of recurrent acute otitis media in otitis-prone children by intermittent prophylax with penicillin. Acta Otolaryngol (Stockh) 1994;1 14:182-7.

\section{Evidence base on managing acute otitis} media had inaccuracies

EDITOR-We think that O'Neill's definition of acute otitis media-inflammation in the middle ear-should be expanded. ${ }^{1}$ The reasons for this become clear if a more complete explanation of the aetiology of acute otitis media is given. Tympanocentesis studies show that viruses can be the sole cause of acute middle ear inflammation in about 20\% of cases-acute secretory otitis media. ${ }^{2}$ Respiratory epithelium is found in both the eustachian tube and the middle ear, and a preceding viral infection may alter the ability of this epithelium to resist subsequent bacterial infection-acute suppurative otitis media. ${ }^{2}$ This partly explains why acute otitis media resolves in $80 \%$ of children without antibiotic treatment. ${ }^{1}$ Unfortunately the clinical presentation and appearance of the tympanic membrane are often identical in the early stages of both acute secretory and acute suppurative otitis media, the gold standard for differential diagnosis being myringotomy.

The practical value of O'Neill's review article is limited because it has no stated guidelines on the management of this common childhood problem. We are concerned about the $20 \%$ of patients whose condition has not improved by the third day and who probably have acute suppurative otitis media. The article gives the impression that there are no serious consequences of untreated acute otitis media, yet otolaryngologists still see cases of perforated ear drums, acute mastoiditis, and chronic suppurative otitis media. The incidence of acute mastoiditis has declined dramatically over the past 50 years because of the use of antibiotics to treat acute otitis media. ${ }^{3}$ The complications of acute mastoiditis are serious and include facial paralysis, labyrinthitis, permanent hearing loss, meningitis, and intracranial abscesses.

On the basis of O'Neill's findings we suggest that patients presenting within 48 hours of onset of acute otitis media should initially be managed by analgesics alone. Patients who continue to have symptoms after the second day or who present with at least a three day history of unresolving acute otitis media should be prescribed a broad spectrum antibiotic

G Sandhu specialist registrar in otolaryngology g.sand@btinternet.com

A Frosh specialist registrar in otolaryngology A Wright professor of otolaryngology Royal National Throat, Nose and Ear Hospital, London WC1X 8DA.

1 O'Neill P. Clinical evidence: acute otitis media. BMJ 1999;319:833-5. (25 September.)

2 Ogra PL, Barenkamp SJ, Mogi G, Murphy TF, Bakaletz LO, Bernstein JM, et al. Recent advances in otitis media. Report of the sixth research conference. Ann Otol Rhinol Laryngol Suppl 1998;174:29-49.

3 Harley EH. Acute mastoiditis in children: A 12 year retrospective study Otolaryngol Head Neck Surg 1997;116.26-30. Ginsburg CM. Acute mastoiditis in infants and children. 
Surgery has a limited but important role in managing acute otitis media

EDITOR-O'Neill's evidence based review of the management of acute otitis media did not mention the limited but important role of surgery in the treatment of this condition. ${ }^{1}$ It also did not mention that the advent of antibiotics has dramatically reduced the incidence of acute mastoiditis in acute otitis media.

As O'Neill pointed out, most cases of acute otitis media are effectively managed with medical treatment and are treated by general practitioners in the community. Surgery should be reserved for acute otitis media refractory to antibiotics, acute otitis media with complications (for example, acute mastoiditis or facial palsy), and recurrent acute otitis media.

Myringotomy alone has been shown to hasten resolution of acute otitis media, especially when antibiotic treatment has not worked. ${ }^{2}$ In addition to providing immediate relief by draining a middle ear abscess, tympanocentesis will provide fluid for microbiological investigation to direct further antibiotic treatment. This is particularly relevant in this time of increasing antibiotic resistance.

Several well conducted studies have shown that adenoidectomy with or without grommet insertion can reduce the incidence of recurrent acute otitis media in children. ${ }^{34}$ Adenoidectomy can improve eustachian tube dysfunction, which is a key factor in the development of recurrent acute otitis media. In addition, adenoidectomy combined with a tonsillectomy may decrease the incidence further. ${ }^{5}$

In conclusion, although medical treatment is important in managing most cases of acute otitis media, surgery has a valuable role in a specific population of children affected by this common condition.

Peter Williamson locum consultant ear, nose, and throat surgeon

Suresh Patel specialist registrar in

otorhinolaryngology

Department of Otolaryngology-Head and Neck Surgery, St Michael's Hospital, Bristol BS2 8EG suresh_patel@hotmail.com

1 O'Neill P. Clinical evidence: acute otitis media $B M J$ 1999;319:833-5. (25 September.)

2 Puhakka H, Virolainen E, Aantaa E, Tuohimaa P, Eskola J, Ruuskanen O. Myringotomy in the treatment of otitis media. Acta Otolaryngol (Stockh) 1979:88;122-6.

3 Paradise JL, Bluestone CD, Rogers KD, Taylor FH, Colborn DK, Bachman RZ, et al. Efficacy of adenoidectomy for recurrent otitis media in children previously treated with tympanostomy tube placement. Results of parallel randomized and nonrandomized trials. JAMA 1990;263:2066-73

4 Casselbrant ML, Kaleida PH, Rockette HE, Paradise JL, Bluestone CD, Kurs-Lasky M, et al. Efficacy of antimicrobial prophylaxis and of tympanostomy tube insertion for prevention of recurrent acute otitis media: results of a randomised clinical trial. Pediatr Infect Dis J 1992;11.278-86.

5 Paradise JL, Bluestone CD, Colborn DK, Bernard BS,

Smith JG, Bluestone CD, Colborn DK, Bernard BS, Smith CG, Rockette HE, et al. Adenoidectomy and adenotonsillectomy for recurrent otitis media: paralle treated with tympanostomy tubes. JAMA 1999;282:987-9.

\section{Surgical treatments should have been discussed}

EDITOR-In his article on clinical evidence in acute otitis media O'Neill has totally ignored surgical treatment. ${ }^{1}$ The second question of the article, "What are the effects of preventive interventions?" should accurately read, "What are the effects of preventive non-surgical interventions?"

The small note at the beginning of the article that myringotomy will not be covered does not permit a total disregard of any surgical intervention. There are numerous randomised clinical trials indicating the efficacy of both inserting tympanostomy tubes (grommets) and adenoidectomy in preventing recurrent acute otitis media. ${ }^{234}$ Sepsis in the sinuses is also often treated to try to prevent recurrent acute otitis media.

Even if none of the published articles satisfy O'Neil's criteria for inclusion, common sense must be used in writing what may be interpreted by some clinicians or managers as a definitive article on the subject. Surgery is often used for treatment of recurrent acute otitis media, and readers are entitled to know the validity or otherwise of this form of treatment. Would it be acceptable to write an article on recurrent acute cholecystitis or treatment of arthritis of the hip without mentioning surgery?

Surely, articles which arguably carry so much weight and may be responsible for change of practice should be coauthored by a contributor from the relevant hospital specialty as well as a general practitioner? This would allow for more than one point of observation on a topic.

Rory Herdman consultant otolaryngologist Roval Berkshire Hospital, Reading RGI 5AN rcdherdman@doctors.org.uk

1 O'Neill P. Clinical evidence: acute otitis media. BMJ 1999;319:833-5. (25 September)

2 Casselbrant ML, Kaleida PH, Rockette HE, Paradise JI Bluestone C, Kurs-Lasky M, et al. Efficacy of antimicrobia prophylaxis and of tympanostomy tube insertion for prevention of recurrent acute otitis media: results of a randomised clinical trial. Paediatr Infect Dis J 1992;11:278-86

3 Gonzalez C, Arnold JE, Woody EA, Erhardt JB, Pratt SR, Getts A, et al. Prevention of recurrent acute otitis media chemoprophylaxis versus tympanostomy tubes. Laryng scope 1986;96:1330-4.

4 Paradise JL, Bluestone CD, Rogers KD, Taylor FH Colborn $\mathrm{K}$, Bach $\mathrm{Ka}$, with tympanostomy tube placement JAMA 1990;268:

\section{Author's reply}

Editor-As Clinical Evidence is an evolving project to be updated every six months, comments are welcome. The management of acute otitis media and recurrent acute otitis media clearly remains controversial, and further studies are needed to resolve some important questions.

Lindbaek highlights the difference between what clinical guidelines suggest and what practising clinicians do. Damoiseaux et al also explored prescribing behaviour in managing acute otitis media. ${ }^{1}$ Around three quarters of the antibiotic prescriptions in their study did not follow nationally recognised guidelines. Medical reasons for prescribing antibiotics were mentioned most often for antibiotic prescriptions that had not been based on guidelines, but in many cases doctors gave non-medical reasons as well. They concluded that appropriate use of antibiotics might not be reached by focusing only on the efficacy of these drugs and that the impact of doctors' awareness of their non- medical motives for prescribing antibiotics on more rational antibiotic prescribing should be investigated further.

Sandhu et al point out that there are no stated guidelines on the management of acute otitis media in the article. This is because Clinical Evidence specifically aims not to make recommendations for reasons made clear in the introduction to the first edition. ${ }^{2}$

Sandhu et al and Williamson and Patel express concerns about complications, particularly mastoiditis, arising from acute otitis media being treated symptomatically rather than with antibiotics. We found no controlled studies that looked at this question. Van Buchem reported that two out of 4860 children treated symptomatically without antibiotics developed mastoiditis. ${ }^{3}$ The recommendations of Sandhu et al are similar to those of the Dutch College of General Practitioners, and at least one report has suggested that outcomes for Dutch patients are as good as for patients treated in countries where antibiotic treatment is almost universal. ${ }^{4}$ This may not be the case in severe infections and in the developing world.

Williamson and Patel and Herdman note that surgical interventions in the management of acute otitis media were conspicuously absent from this, the first, edition of Clinical Evidence. Later editions will present evidence on myringotomy, adenoidectomy, and adenotonsillectomy. This fact was not made clear in the opening paragraph of the article and was an error Future editions will differentiate surgical and non-surgical interventions and look more closely at evidence on managing acute otitis media in children under the age of 2 years.

Paddy O’Neill general practitioner

Norton Medical Centre, Stockton on Tees TS20 1AN

1 Damoiseaux R, de Melker RA, Ausems MJ, van Balen FA. Reasons for non-guideline-based antibiotic prescription for acute otitis media in the Netherlands. Fam Pract 1999;16:50-3.

2 Godlee F Goldman D, eds Clinical Evidence Vol 1. London: BMJ Publishing Group, 1999:vii

3 Van Buchem F, Peeters M, van't Hof M. Acute otitis media: a new treatment strategy. BMJ 1985;290:1033-7.

4 Froom J, Culpepper L, Grob P, Bartelds A, Bowers P, Bridges-Webb C, et al. Diagnosis and antibiotic treatment of acute otitis media: report from International Primary Care Network. BMJ 1990;300:582-6.

\section{Screening for hereditary haemochromatosis should be implemented now}

EDITOR-The editorial by Haddow and Bradley on population screening for haemochromatosis concludes that now is too early to start population screening because of uncertainties about the proportion of homozygotes who will express symptoms of the disease. ${ }^{1}$ Haemochromatosis has been recognised as a clinical entity for over 150 years, but the gene that is mutated was not identified until 1996. Clinical haemochromatosis, defined by the presence of abnormal serum iron variables, has consistently been estimated to affect between 1 in 200 and 1 in 500 white people. ${ }^{23}$ The incidence of homozygotes for the more severe and 
common of the two mutations, C282Y, has been shown to be about 1 in 250 in all white populations studied. At least half of those with the major predisposing genotype (C282Y homozygosity) are likely to develop symptoms and signs of the disease.

A likely "favourable ratio" of one individual benefiting for every two in whom prophylactic phlebotomy is started on the basis of genotype tips the scales in favour of population based genetic screening. If gene testing is offered many individuals at high risk will be identified before symptoms develop and therefore will avoid serious but preventable illnesses.

We believe that genetic population screening is a correct strategy because haemochromatosis is common, preventable, and treatable. Screening before symptoms develop would result in it becoming rare. ${ }^{4}$ Testing can be undertaken in adults aged below 30, and prevention (regular blood donation) is not onerous. A simple and inexpensive mouthwash test is all that is required for DNA analysis for the affected gene. Unlike with other gene tests, there are few ethical issues to be balanced against the clinical benefits.

The public health issue revolves around the risk-benefit ratio, as is the case for screening for high cholesterol concentrations or hypertension. The link between the risk factor (C282Y homozygosity) and disease expression is tighter for haemochromatosis, and the medical management (regular blood donation) is far less onerous and costly than the lifelong daily drug treatment prescribed for hypertension or hypercholesterolaemia. We believe that to benefit all those at risk there is an ethical imperative to implement screening for the major mutation causing haemochromatosis now, rather than wait years for confirmation of what is currently known - that at least half of those with the predisposing genotype will develop some form of the disease.

Katrina Allen paediatric gastroenterologist Robert Williamson director

Murdoch Institute, Royal Children's Hospital, Parkville, 3052, Victoria, Australia

allenk@cryptic.rch.unimelb.edu.au

1 Haddow JE, Bradley LA. Hereditary haemochromatosis: to screen or not. BMJ 1999;319:531-2. (28 August.)

2 Leggett BA, Halliday JW, Brown NN, Bryant S, Powell LW. Prevalence of haemochromatosis amonost asymptomatic Australians. Br J Haematol 1990;74:525-30.

3 Australians. Br J Haematol 1990;74:525-30. Bradley LA, Haddow JE, Palomaki G, Haddow J. Robertson N, Ferrie R. Hereditary haemochromatosis mutation frequencies in the general population. $J$ Med
Screen 1996:3:171-7.

4 Allen KJ, Williamson R. Should we genetically test everyone for haemochromatosis? J Med Ethic 1999;25:209-14

\section{Social and productive activities in elderly people}

\section{Activities have been confused}

EDITOR-Glass et al have concluded that in elderly people "social and productive activities that involve little or no enhancement of fitness lower the risk of mortality all cause as much as fitness activities do," and that "activity may confer survival benefits through psychosocial pathways." The study design, however, incorporates a misconception that pervades many studies into physical activity.

Neither high levels of cardiorespiratory fitness nor participation in vigorous activities that promote cardiorespiratory fitness are necessary to decrease morbidity and mortality. The main health related variable is the volume, rather than the frequency, intensity, or duration of the activity. Whether the activity is planned (as in sport), or incidental (as in gardening), is obviously immaterial. The body does not care whether the physical activity is undertaken as sport, exercise, hobbies, translocation, or household chores.

In this study, most activities categorised as social and productive can entail significant levels of incidental physical activity. Of the 11 activities mentioned, only day or overnight trips and playing cards, games, or bingo are likely to be completely sedentary. The risk is high that this analysis is seriously confounded by the presence of health enhancing physical activities in all three categories. Glass et al are obviously aware of this as they have omitted "shopping" and "gardening" from one of the analyses. We cannot, however, discount the possibility that all the activities categorised as productive (gardening, preparing meals, shopping, unpaid work, paid work, and other employment) might incorporate significant amounts of physical activity. Significant risk reduction is achieved at a level of $150 \mathrm{kcal} /$ $\mathrm{kg} /$ day of expenditure of energy through activity. ${ }^{2}$ This level is embodied in current health related guidelines for physical activity, ${ }^{4}{ }^{4}$ which recommend 30 minutes of brisk walking per day. Sufficient energy expenditure can be just as easily accrued through incidental physical activity as by predetermined sports and exercise activity.

The distribution of total physical activity between the three groups in this study remains uncertain, but the findings must be highly questionable. Future health focused studies incorporating physical activity should appreciate that there are many potential pathways to achieving targets of health related physical activity and should not be distracted by notions of sport, fitness, and fitness training.

Chris Riddoch senior lecturer, exercise and health science

Department of Exercise and Health Sciences, University of Bristol, Bristol BS8 1TN chris.riddoch@bristol.ac.uk

1 Glass TA, de Leon CM, Marottoli RA, Berkman LF. Population based study of social and productive activities as predictors of survival among elderly Americans. $B M$ 1999-319:478-83. (21 August)

2 Paffenbarger RS, Hyde RT, Wing AL, Hsieh C. Physical activity, all-cause mortality, and longevity of college alumni. $N$ Engl J Med 1986;314:605-13.

3 Department of Health. Strategy statement on physical activity. London: DoH, 1996.

4 Department of Health and Human Services. Physical activity and health: a report of the Surgeon General. Pittsburgh, PA: Department of Health and Human Services, Centers for Disease Control and Prevention, National Center for Chronic Disease Prevention and Health Promotion, 1996.

\section{Activity (occupation) is important for} survival

EDITOR-Glass et al's paper on the relation between activity and survival in older Americans adds to our understanding of how health affects, and is affected by, engagement in purposeful, meaningful activity or what occupational therapists term occupation. Although the occupational therapy profession was founded on a belief in this relation, only relatively recently has it been examined more critically.

Glass et al's paper contributes to the growing body of research based knowledge that can now help us better understand the relation between occupation and health. A similar project was undertaken by Iwarsson et al, who used existing data from a 25 year longitudinal investigation of elderly people in Sweden. ${ }^{2}$ In that study significant differences in survival were found between women who were more active and less active.

In a more rigorous project with a randomised design Clark et al compared groups of elderly people living in Los Angeles. ${ }^{3}$ One group followed an activity programme led by occupational therapists, one group followed an activity programme led by non-occupational therapists, and one group served as controls. Interestingly, the authors found no significant differences between the control group and the group who followed the non-occupational therapy programme. The occupational therapy intervention, however, had significant benefits "across various health, function, and quality of life domains."

Of note in the current study is the finding that social and productive activities were just as effective in reducing the risk of death as fitness activities. ${ }^{1}$ As the authors suggest, this is probably due to a wide range of mechanisms and provides further evidence of the complex nature of occupations. Indeed, Rudman et al found that elderly Canadians considered activity to be any form of mental, social, or physical types of doing. ${ }^{4}$ The findings also suggested that sense of control was an important mediator of the health benefits of engagement in occupation. For these reasons a full understanding of the relation between occupation and health can be achieved only by considering occupations from many perspectives: transcendental, symbolicevaluative, sociocultural, information processing, biological, and physical.

It is exciting and encouraging that other disciplines are investigating the occupational nature of people, and I look forward to future research.

Matthew Molineux lecture

Discipline of Occupational Therapy, College of Ripon and York St John, York YO31 7EX m.molineux@ucrysj.ac.uk

1 Glass TA, de Leon CM, Marottoli RA, Berkman LF. Population based study of social and productive activities as predictors of survival among elderly Americans. BMJ 1999;319:478-83. (21 August)

2 Iwarsson S, Isacsson A Persson D, Schersten B. Occupation and survival: a 25-year follow-up study of ageing population. Am J Occup Ther 1998;52:65-70. 
3 Clark F, Azen A, Zemke R, Jackson J, Carlson M, Mandel D, et al. Occupational therapy for independent-living older adults. JAMA 1997;278:1321-6.

4 Rudman D, Cook J, Polatajko H. Understanding the potential of occupation: a qualitative exploration of seniors' perspectives on activity. Am J Occup Ther 1997;51:640-50.

5 Clark F, Parham D, Carlson M, Frank G, Jackson J, Pierce D, et al. Occupational science: academic innovation in the service of occupational therapy's future. Am J Occup Ther 1991;45:300-10

\section{Self rated health is important predictor} of mortality

EDITOR-Glass et al add important information to the field of gerontology and enlarge our scope for assessing and caring for older people. ${ }^{1}$ They note the possibility that activity levels measured at baseline were actually measuring health status and attempted to examine this in subsequent analyses by eliminating deaths in the first five years of follow up.

They do, however, not deal adequately with the probability that "those who can, do, and those who cannot, don't do." Since individuals self select for the observed social and productive activities, any factors pertinent to self selection, such as wellbeing or self health appreciation, may contribute to the outcome (survival). Several longitudinal community cohort studies observed mortality after a self health evaluation. ${ }^{2-4}$ Some followed the cohort well beyond five years, ${ }^{23}$ and some adjusted the self appraisal further with a concurrent medical appraisal. ${ }^{2}$ Almost without exception, global self rated health was found to be an important predictor of mortality. The differences of mortality in elderly people between those with highest and lowest health self evaluations proved to be about $20-35 \%$, equal to or greater than the "protective" reductions in mortality both for social and productive activities and for increased physical activity. Does this perhaps mean that a common underlying factor, not readily measured by surveys (for example, subtle perceptions of energy level, absence of substantial preclinical health problems), may prompt one to evaluate self health positively and also to participate in more social and productive activity or greater physical activity?

The findings of Glass et al should prompt broader research into these neglected areas that may be critically important in longevity. It is, however, too soon fully to endorse a premise that improving social and productive activities in otherwise unmotivated, inactive elderly people would extend life. As practitioners, most of us have supported productive activities of our older patients. Without better confirmation of cause and effect, I am not sure we are yet in a position to press all indolent elderly people to become actively involved as a health measure; such an intervention could be harmful rather than salutary.

Gerson T Lesser assistant professor Department of Geriatrics and Adult Development, Mount Sinai School of Medicine, Jewish Home and Hospital, New York, NY 10025, US glesser@jhha.org

I Glass TA, de Leon CM, Marottoli RA, Berkman LF. Population based study of social and productive activities as predictors of survival among elderly Americans. BMJ 99;319:478-83. (21 August)

2 Inchingolo GM. Self-perception of health and survival. A 10-year follow-up among Italians aged over sixty. Minerva Medica 1997;88:15-23.

3 Idler EL, Benyamini Y. Self-rated health and mortality: a review of twenty-seven community studies. J Health Soc Behavior 1997;38:21-37.

Van Doorn C, Kasl, SV. Can parental longevity and self-rated life expectancy predict mortality among older persons? Results from an Australian cohort. $J$ Gerontol 1998;53B:S28-S34.

\section{Authors' reply}

EDITOR-Riddoch thinks that the beneficia effects of the activities we studied may partly result from the effects of incidental physical activity. An unknown fraction of the effect of our activities results from these known physiological pathways. In the case of social activities, this fraction is probably rather small. There may, however, be an important residual benefit that results from other, lesser known, psychosocial pathways. The data needed to test this hypothesis fully do not exist. All our evidence from this study and others, however, indicates that more or less sedentary social and productive activities are as protective as physical activities. ${ }^{1}$

Moreover, we are aware that many scientists will discount these findings as simply the confounding influence of "incidental physical activity." We do not have the data to rule this out. Psychosocial processes may be involved. For example, the evidence in favour of the influence of the interaction of social networks on mortality is quite strong. New evidence shows that psychosocial factors have a direct impact on physiological systems. ${ }^{3}$ The reverse may also be true. In many studies of physical activity and health, the benefits of physical activity are confounded by the psychosocial consequences of what Molineux calls "occupation." This may help to understand the recent findings that "lifestyle" interventions are as effective in various populations as exercise interventions. ${ }^{45}$

We agree with Lesser that self rated health may be an additional factor impinging on the relation between activity and health. Self rated health may be an effect modifier or on the causal pathway. We believe that the latter is more plausible and decided not to include self rated health as a control variable in this single-equation analysis. We have, however, added that variable to the main models presented in the original paper (with the understanding that this may not be the ideal specification). The regression coefficients change only slightly after controlling for self rated health. The effect of social activities drops from -0.069 to $-0.061(\mathrm{P}<0.001)$; fitness activities from -0.078 to $-0.066(\mathrm{P}=0.011)$; and productive activities from -0.112 to -0.103 $(\mathrm{P}<0.001)$. In each case the effect is attenuated slightly, although the overall pattern of influence is the same.

We agree with Lesser that it is too soon to endorse a premise that increasing socia and productive activities in otherwise unmotivated, inactive elderly people would extend life. This is not a clinical trial, so definitive conclusions about cause and effect are unwarranted. We thank Molineux for pointing out important earlier work in occupational therapy, and we regret not having relied more on that literature, especially Clark's study, in our manuscript.

Thomas A Glass assistant professor

Department of Health and Social Behavior, Harvard School of Public Health, Boston, MA 02115, USA

1 Bassuk SS, Glass TA, Berkman LF. Social disengagement and incident cognitive decline in community-dwelling elderly persons. A Ands of Internal Medicine 1999;131(3): erly per

2 House JS, Landis KR, Umberson D. Social relationships and health. Science 1988:241:540-5.

3 Uchino BN, Cacioppo JT, Kiecolt-Glaser JK. The relationship between social support and physiological processes: review with emphasis on underlying mechanisms and implications for health. Psychological Bulletin 1996; 119(3):488-531.

4 Dunn AL, Marcus BH, Kampert JB, Garcia ME, Kohl HW, Blair SN. Comparison of lifestyle and structured interventions to increase physical activity and cardiorespiratory fitness: a randomized trial. JAMA 1999;281(4):327-34.

5 Andersen RE, Wadden TA, Bartlett SJ, Zemel B, Verde TJ, Franckowiak SC. Effects of lifestyle activity vs structured aerobic exercise in obese women: a randomized trial. JAMA 1999;281(4):335-40.

6 Clark F, Azen SP, Zemke R, Jackson J, Carlson M, Mandel $\mathrm{D}$, et al. Occupational therapy for independent-living older adults. A randomized controlled trial JAMA 1997;278(16):1321-6.

\section{Health promotion activity should be retargeted at secondary prevention}

EDITOR-In their short report of a five year follow up of a trial of individual advice on lifestyle modification Cupples and McKnight report that "most of the benefits identified at the end of two years had worn off" at five years. ${ }^{1}$ They fail, however, to report that fewer deaths occurred in the intervention group (relative risk $0.73 ; 95 \%$ confidence interval 0.52 to 1.03 ).

Although this finding is of only borderline significance, it is consistent with results of previous systematic reviews of randomised controlled trials that have also shown long term reductions in mortality. ${ }^{23}$ Changes in cardiovascular risk factors in this trial were disappointingly small at five years, but smoking rates were lower, and use of antianginal drug treatments higher, in the intervention group. No information is given on the use of antiplatelet drugs, statins, or revascularisation, which might be expected to have an impact on mortality.

Evidence for a possible lifesaving effect of individual advice on behavioural modification (known as cardiac rehabilitation after myocardial infarction) in high risk people, although derived from small and often flawed trials, supports targeting interventions on those who have already had a myocardial infarction or have angina, diabetes, or hypertension. A large multicentre randomised controlled trial of comprehensive cardiac rehabilitation funded by the NHS research and development's national programme on cardiovascular disease is under way and should provide definitive evidence for a national service framework in coronary heart disease.

In people at relatively low risk of cardiovascular disease randomised controlled 
trials, quasiexperimental studies, and before and after studies have failed to provide any convincing evidence of a reduction in morbidity or mortality from individual or family advice on health behaviour modification. $^{34}$ Consequently, retargeting currently fruitless health promotion activity at secondary prevention should offer much better value for money.

Shah Ebrahim professor in epidemiology of ageing George Davey Smith professor of clinical

epidemiology

Department of Social Medicine, University of Bristol, Bristol BS8 2PR

shah.ebrahim@bristol.ac.uk

Rachel Bennett senior house officer

Frenchay Hospital, Bristol BS16 1LE

1 Cupples ME, McKnight A. Five year follow up of patients at high cardiovascular risk who took part in a randomised controlled trial of health promotion. BMJ 1999;319:687-8. (11 September.)

2 NHS Centre for Reviews and Dissemination. Cardiac rehabilitation. Effective Health Care 1998;4:7-9.

3 Ebrahim S, Davey Smith G. Health promotion in older people for cardiovascular disease prevention-a systematic reviow and meta-analysis. London: Health Education Authority, 1996.

4 meta-analysis. London. Health Education Authority, 1996.

Ebrahim S, Davey Smith G. A systematic review and metaanalysis of randomised controlled trials of health promotion for prevention of coronary heart disease in
adults. BMJ 1997;314:1666-7.

\section{Randomised controlled trials in psychiatry}

Trials show that psychotherapy is effective for wide range of psychological conditions

EDITOR-In his article on randomised controlled trials in psychiatry Andrews concludes that dynamic psychotherapy is not efficacious and that drugs and cognitive behaviour therapy are more beneficial. ${ }^{1}$ In fact, results from randomised controlled trials show that psychotherapy is an effective treatment for a wide range of psychological conditions. ${ }^{2}$ Furthermore, the results of a recent randomised controlled trial of brief psychodynamic-interpersonal therapy shows that this may be a cost effective intervention for patients who have not responded to conventional psychiatric treatment. ${ }^{3}$ In previous research this therapy was shown to be superior to supportive listening alone, ${ }^{4}$ in contrast to Andrews' claim that no trial has "been shown to be superior to talking to a mature and kindly adviser."

In general, the debate about the evidence base for psychotherapy has moved on from questioning its overall effectiveness and is now considering more specific issues such as appropriate dosages, optimal delivery, and cost effectiveness. I agree with Andrews that what people think about a treatment can be as important as the evidence of its efficacy. If psychiatry is to accept and implement evidence based practice then the available evidence must be presented objectively.

Helen Barker specialist registrar in psychotherapy Red House Psychotherapy Services, Manchester M27 5FG

Helen.barker@cwcom.net
1 Andrews G. Randomised controlled trials in psychiatry: important but poorly accepted. BMJ 1999;319:562-4. (28 August)

2 Roth AD, Fonagy P. What works for whom? A critical review of psychotherapy research. New York: Guilford Press, 1996.

3 Guthrie E, Moorey J, Margison F, Barker H, Palmer S, McGrath G, et al. Cost-effectiveness of brief psychodynamic-interpersonal therapy in high utilizers of psychiatric services. Arch Gen Psychiatry 1999;56:519-26.

4 Guthrie E, Creed F, Dawson D, Tomenson B. A controlled trial of psychological treatment for the irritable bowel syndrome. Gastroenterology 1991;100:450-7.

\section{Scarcity of evidence is not necessarily evidence against long term psychodynamic psychotherapy}

EDITOR-Andrews makes the misleading and unreferenced statement in his article on randomised controlled trials in psychiatry that "long term psychodynamic psychotherapy ... has not been shown to be superior to talking to a mature and kindly adviser." To apply randomised controlled trials to long term psychotherapeutic approaches is notoriously difficult, and we know of no trial that has done this using treatment by non-expert therapists as a control condition. An evidence based review of psychotherapy services in England does not support Andrews' views on dynamic psychotherapy and warns against regarding scarcity of evidence as evidence against. ${ }^{2}$ Most randomised controlled trials in psychotherapy study short term treatments (12-20 sessions) and usually show no or marginal differences in efficacy between cognitive and dynamic treatments. Effect sizes are generally small albeit clinically significant; follow up is short. With these brief interventions any coherent, skilfully applied therapy will apparently have moderate, though not necessarily enduring, effects. Reviews habitually exclude all but studies of atypical, highly homogeneous patient populations.

The small amount of psychoanalytic psychotherapy available in the NHS is mostly used to treat patients referred to tertiary centres who have moderate to severe persisting disturbance-a diagnostically heterogeneous group of patients who have frequently not responded to short term cognitive treatments. Andrews' pessimistic views on dynamic psychotherapy are out of date, as several excellent randomised controlled trials are in progress or recently published showing the advantage of psychodynamic psychotherapy over other approaches for severe disorders. Bateman and Fonagy, for example, have shown the value of a psychoanalytic approach based in day hospitals for patients with severe personality disorder. ${ }^{3}$ Sandahl et al have shown the superiority of psychodynamic group psychotherapy over cognitive behavioural therapy in reducing alcohol intake in patients dependent on alcohol, as judged by abstinence at 15 months of follow up. ${ }^{4}$ These studies and others show change not just in wellbeing and in interpersonal relationships but in reduced use of health and social services.

In practice, cognitive behavioural therapy may not be acceptable to patients. The London depression intervention study compared three treatments for severe depression: systemic or dynamic couple therapy, drug treatment, and cognitive therapy. ${ }^{5}$ Most patients allocated to the cognitive therapy found the treatment unacceptable and dropped out. The final comparison favoured couple therapy over drug treatment overall, even after two years. These results challenge the idea that an evidence based approach to the treatment of depression can rely exclusively on drug treatments and cognitive behavioural therapy.

Jane Milton consultant psychiatrist janemilton@compuserve.com

Philip Richardson consultant clinical psychologist Robert Hale consultant psychiatrist Tavistock and Portman NHS Trust, London NW3 5BA

1 Andrews G. Randomised controlled trials in psychiatry: important but poorly accepted. BMJ 1999:319:562-4. (28 August.)

2 Parry G, Richardson A. NHS psychotherapy services in England: review of strategic policy. London: Department of Health, 1996.

3 Bateman A, Fonagy P. The effectiveness of partial hospitalisation in the treatment of borderline personality disorder-a randomised controlled trial. Am J Psychiatry (in press).

4 Sandahl C, Herlittz K, Ahlin G, Rönnberg S. Time-limited group therapy for moderately alcohol dependent patients: a randomised controlled trial. Psychotherapy Research 1998;8:361-78.

5 Leff J, Vearnals S, Brewin C, Wolff G, Alexander B, Asen E, et al. The London Intervention Trial: an RCT of antidepressants versus couple therapy in the treatment and maintenance of depressed people with a partner Clinical outcome and cost. Br J Psychiatry (in press).

\section{Evaluation of questionnaire on cancer family history in general practice}

\section{Principal role of primary care is not to seek out those at increased genetic risk}

EDITOR-I am concerned about the implicit message underlying the study by Leggatt et al evaluating a questionnaire on cancer family history to identify patients at increased genetic risk - namely, the promotion of family history screening in primary care. ${ }^{1}$ The authors seem to assume that evidence is sufficient to justify proactively identifying people at increased genetic risk of cancer. However, assessment of family history falls far short of the Wilson and Junger criteria for a screening test.

The study of colonoscopy in patients with hereditary non-polyposis coli was a non-randomised controlled trial that did not find a significant effect on mortality at 10 years. ${ }^{2}$ The study of mammography was an observational study from a single cancer family clinic. ${ }^{3}$ Unfortunately, this is the best available evidence to support these surveillance methods in people at increased genetic risk of colorectal or breast cancer.

The authors acknowledge that a postal questionnaire is a poor screening tool because of the low response rate achieved with this method, but they suggest its use at patient registration instead. Surely we must wait for stronger evidence to support surveillance or chemoprevention in people at increased genetic risk of cancer? Until then the principal role of primary care 
should be to manage appropriately patients who present with concerns about their family history of cancer and not to seek out actively those at increased genetic risk. Doctors should not raise people's anxieties about their family history of cancer until they can offer their patients proved interventions.

Jon Emery Cancer Research Campaign primary care oncology research fellow

Imperial Cancer Research Fund General Practice Research Group, University of Oxford, Institute of Health Sciences, Oxford OX3 7LF

jon.emery@green.ox.ac.uk

1 Leggatt V, Mackay J, Yates JRW. Evaluation of questionnaire on cancer family history in identifying patients a increased genetic risk in general practice. BMJ increased genetic risk in
1999;319:757-8. (18 September.)

2 Jarvinen HJ Mecklin JP, Sistonen P. Screening reduces Jarvinen $\mathrm{HJ}$, Mecklin JP, Sistonen P. Screening reduce colorectal cancer rate in families with hereditary non-polyposis colorectal cancer. Gastroenterology

3 Lalloo F, Boggis CR, Evans DG, Shenton A, Threlfall AG Howell A. Screening by mammography, women with a family history of breast cancer. Eur J Cancer 1998;34
$937-40$.

\section{General practitioners reassure those at low risk and refer those at high risk}

EDITOR-The study by Leggatt et al is an important contribution to the research defining the role of primary care in genetics. ${ }^{1}$ It confirms previous research which showed that it is feasible for a general practitioner (with an interest) to take and analyse a genetic family history, whether verbally or by questionnaire. ${ }^{2}$

The general practitioners in these studies were able to reassure patients at low risk and refer those at higher risk. This is identical with their role in other branches of medicine. Most primary care workers, however, currently elicit information about family history in the consultation as a risk factor for a disease- for example, breast cancer and heart disease- or for social and cultural reasons. Generally, general practitioners are not yet confident to use the family history as a genetic assessment tool and want more education on this subject.

The increase in referrals by general practitioners to genetic clinics, especially family cancer clinics, implies that more patients are presenting in primary care with a concern about a genetic problem. The size of the current workload in primary care is, however, unknown as only one prospective study, from the Netherlands, has reported the rate of presentation to general practitioners of such problems. ${ }^{4}$ The response rate in the study of Leggatt et al is disappointing if genetic risk is now on patients' agenda, but it is in keeping with the rates in other genetic screening studies in primary care. ${ }^{25}$

The reason for this may be because only a small proportion of the population are aware of genetic issues or those who are aware may think that genetic risk is not relevant to them. Alternatively, the patients who respond or present to their general practitioner may be those at high risk. Whatever the reason, patients in primary care should start to receive the benefits of the advances in genetics, and research should continue to ensure that services are imple- mented only when the benefits outweigh the risks, especially in the context of screening and case finding.

Peter Rose general practitioner

Mill Stream Surgery, Benson, Oxfordshire OX10 6RI

1 Leggatt V, Mackay J, Yates JRW. Evaluation of questionnaire on cancer family history in identifying patients at increased genetic risk in general practice. $B M J$ 1999;319:757-8. (18 September.)

2 Rose P, Humm E, Hey K, Jones L, Huson SM. Family history taking and genetic counselling in primary care. Fam Pract 1999;16:78-83.

Watson EK, Shickle D, Qureshi N, Emery J, Austoker J. The "new genetics" and primary care: GPs views on their role and their educational needs. Fam Pract 1999;16:420-5.

4 De Bock GH, Perk DC, Oosterwijk JC, Hageman GC, De Bock GH, Perk DC, Oostem jk JC, Hageman GC, Kievit J, Springer MP. Women worried about their familia breast cancer risk - a study on genetic advice in general
practice. Fam Pract 1997;14:40-3.

, Silver A, Mathew C, Bobrow $\mathrm{M}$, et al. Uptake of cystic fibrosis testing in primary care: supply push or demand pull? BMJ 1993;306:1584-6.

\section{Authors' reply}

EDITOR-Emery is concerned that our short report promotes family history screening for cancer in primary care. This was not our intention, and we agree that for breast and colorectal cancer more data are needed to confirm benefit. In the expectation that evidence for benefit will be forthcoming for at least some familial conditions, work needs to start on developing effective strategies for ascertaining those at increased genetic risk in primary care. Our study was designed to assess one approach using breast and colorectal cancer as a model. When it comes to implementation, we agree with Rose that it would be feasible for general practitioners to provide family history screening but only if they are given the necessary resources and clear guidelines for interpreting the information

Emery raises the important issue of whether asking about family histories makes patients anxious. As part of our study, we measured the degree of general anxiety and worry about cancer before completion of the family history questionnaire and 4-6 weeks after patients were given their risk assessment. We found no change in general anxiety either in those deemed to be at low risk or in those with potentially significant family histories. However, the pre-existing perception of their personal risk of developing cancer was higher in patients with potentially significant family histories than in other patients. ${ }^{1}$ This lends support to our subjective assessment that many patients with significant family histories already recognise that they may be at increased risk and appreciate an opportunity to obtain advice about it.

Virginia Leggatt general practitioner East Barnwell Health Centre, Cambridge CB5 8SP

James Mackay consultant in cancer genetics

Department of Oncology, Addenbrooke's Hospital, Cambridge CB2 2QQ

John R W Yates university lecturer

Department of Medical Genetics, University of Cambridge, Addenbrooke's Hospital, Cambridge CB2 2QQ

1 Leggatt V, Mackay J, Marteau TM, Yates JRW. The psychological impact of a cancer family history questionnaire completed in general practice. J Med Genet (in press).

\section{Magnetic resonance imaging is preferred in diagnosing suspected cerebral infections}

EDitor-In their lesson of the week Fitzpatrick and Gan state that contrast enhanced computed tomography is currently the preferred investigation in diagnosing cerebral abscess. ${ }^{1}$ They describe the role of magnetic resonance imaging in such diagnosis as unclear, citing a 1988 comparative study of two cases as proof. ${ }^{2}$ We use magnetic resonance imaging as the preferred imaging technique in patients with suspected cerebral infections. ${ }^{3}$ It has improved resolution with multiplanar capability, and it is far more sensitive at detecting subtle white matter abnormalities as may be found in patients with herpes simplex encephalitis. We accept that computed tomography may be more widely available in the United Kingdom, though we do not necessarily concur that it is the best investigation.

Fitzpatrick and Gan point out that cerebral abscess is a rare condition with appreciable morbidity and mortality, and early diagnosis is mandatory. ${ }^{1}$ Unfortunately, many patients with cerebral abscess present with clinical and radiological features identical with stroke. Stroke is common, and most centres do not use intravenous contrast medium in patients who have had a suspected stroke. If the history is of a sudden onset of neurological loss without clinical features suggestive of a cerebral abscess (such as fever and leucocytosis) we use unenhanced computed tomography. Acute cerebral infarction can cause a mass effect, and unless the possibility of alternative disease is raised by the referring clinician then these patients may well be misdiagnosed as having had cerebral infarction. If the pattern of oedema is atypical for cerebral infarction, or if the patient's condition deteriorates and has features suggestive of an abscess, then further imaging with either gadolinium enhanced magnetic resonance imaging or contrast enhanced computed tomography is required.

The authors state that without expert neuroradiological advice "it is too easy to interpret findings as representing cerebral infarction." We agree that expert advice is often helpful. We emphasise, however, that cerebral abscess and infarction can appear identical on unenhanced computed tomography. Therefore clinical suspicion of infection or an atypical history of stroke must be communicated to the radiology department so that appropriate imaging can be performed. We believe that this should ideally be gadolinium enhanced magnetic resonance imaging, or contrast enhanced computed tomography if magnetic resonance imaging is unavailable.

N D Marchbank consultant radiologist

D C Howlett consultant radiologist D F Sallomi consultant radiologist

D V Hughes consultant radiologist

Eastbourne District General Hospital, Eastbourne,

East Sussex BN21 2UD 
1 Fitzpatrick MO, Gan P. Contrast enhanced computed tomography in the early diagnosis of cerebral abscess. $B M$ 999;319:239-40. (24 July.)

2 Saleh J, Afshar F. Comparative study of brain abscess by computed tomography and magnetic resonance imaging: report of two cases. Br J Neurosurg 1988;2:517-22.

3 Schroth G, Retzschmar K, Gawehn J, Voigt K. Advantage of magnetic resonance imaging in the diagnosis of cerebral infections. Neuroradiology 1987;29:120-6.

\section{All journals from the BMJ Publishing Group should be free online}

EDITOR-During last October I received my $B M J$ in a wrapper that proudly proclaimed that many journals published by the BMJ Publishing Group, including Heart, Gut, Thorax, and $J M G$, were now online. I thought this a useful innovation and looked forward to getting access to them. I am a full time, extremely busy general practitioner-as we all are-and access to any kind of information is therefore extremely useful. There had been a lot of interest in a recent article in Thorax about diet and obstructive airways disease. Naturally, I wanted to look at it, and I assumed that I would be able to gain access to it through the $B M / \mathrm{s}$ s website or Medline.

After spending a frustrating 25 minutes seeking access I had to give up. I managed to get an article from a newspaper online about the article. I telephoned the helpline advertised on the outside cover of the $B M$ J and was told that this service was available only to people who subscribe to the journals, which I found astonishing. This is unnecessary protectionism.

Many prestigious journals are available online that rely on money from subscriptions to keep them going. You can access the New Scientist's site and read any article from the journal for any week that you wish, and indexing of back copies over the past two years is also excellent. You do not need to buy New Scientist to do this. The publishers realise that because they produce a good magazine people will not stop buying it to read it online. Everyone knows that it is extremely tiring and difficult to read a magazine online.

I do not believe that the journals published by the BMJ Publishing Group would lose any subscriptions by becoming freely available online to anybody who subscribes to the BMJ. Am I as a general practitioner really expected to subscribe to 10 journals, all of which could have highly relevant and interesting information that I might need to access, when I am already a member of the BMA and support the BMJ Publishing Group through my subscriptions? I would be grateful if this situation could be remedied as soon as possible. You should need only to enter your Medline password and identification to gain access to these journals, and I am sure every member of the BMA would agree about this.

A E Dobbin general practitioner

Brunton Place Surgery, Edinburgh EH7 5EG

\section{Editor's reply}

I am pleased that we are able to provide free access to the $B M J$ s website at the moment, and I hope very much that we will be able to keep it that way. But it is not certain that we will be able to do so. Indeed, nothing is certain about the electronic future of journals. It is not even certain that many of them have a future.

Although the $e B M J$ is available free to everybody, we have not been able to follow this model with our specialist journals. They are free to those who receive paper copies (including members of societies with which we co-own some of the journals), but we cannot at the moment make them free to everybody. We do plan, however, to experiment with "paying per view," which means that people like Dr Dobbin would be able to get access to a particular article very cheaply-probably at less cost than getting an article from a library.

We are in an experimental phase in the BMJ Publishing Group, and the specialist journals have a completely different source of income from the BMJ. Most of their income comes from subscriptions, making them much more vulnerable than the $B M]$ to the cancellation of subscriptions. Dr Dobbin is right that people do not want to read onscreen, and my hypothesis (no more than that) is that if people read more than $15 \%$ of a publication then they may want a paper copy. If I'm right, a publication such as New Scientist (and probably the $B M J$ ) has little to fear, but it may be different for journals that are comprised largely of research articles.

Dr Dobbin, like every BMA member I have ever met, imagines that some, perhaps even much, of his subscription goes on the $B M J$. In fact, none of it does. The journal has income from classified and display advertising and from subscriptions from nonmembers. These underwrite the cost of the $B M J$, and the whole publishing group manages in addition to put around $£ 2 \mathrm{~m}$ a year into the BMA's reserves. The BMA wants us to carry on doing that, which is one of the reasons why we cannot make all journals free to everybody.

\section{Complementary medicine must} be research led and evidence based

EdiToR-The ABC of Complementary Medicine is welcome. ${ }^{1}$ Ernst has drawn attention to an important issue in relation to complementary and alternative medicine. ${ }^{2}$ He previously showed that $0.08 \%$ of the total research budget in the United Kingdom is being spent on complementary and alternative medicine. ${ }^{3}$ The Foundation for Integrated Medicine's report emphasises the importance of an appropriately resourced national agenda for research into complementary and alternative medicine and suggests possible areas for research. ${ }^{4}$ The deans of all medical schools in the United Kingdom were asked to comment on the initial draft of this document, and those who responded unanimously highlighted the need for more research in association with an appropriate structure to carry such a policy forward.
If we are to develop an integrated approach that will allow us to combine the best of conventional medicine and complementary and alternative medicine in order to provide an informed choice for our patients, then it must be research led and evidence based. In the United States the Office of Alternative and Complementary Medicine within the National Institutes of Health has now become a centre in its own right, providing both a structure and appropriate funding ( $\$ 50 \mathrm{~m}(£ 33 \mathrm{~m})$ per annum) that will sustain a concerted research effort.

Much research in complementary and alternative medicine originates from the United Kingdom. Without appropriate support, however, this embryonic academic discipline will certainly flounder. Research funding is sourced either directly through tax revenue or through charitable contributions; the public's use of complementary and alternative medicine is increasing dramatically throughout the Western world. ${ }^{5}$ Public sources of funding should be responsive to patient need, and therefore more should be made available to develop research structures within complementary and alternative medicine.

The development of, and investment in, research into complementary and alternative medicine is an important national priority in response to the public's growing use of these therapeutic interventions.

G T Lewith honorary senior research fellow University of Southampton, Southampton SO16 6YD

E Ernst director

Department of Complementary Medicine,

University of Exeter, Exeter EX2 4NT

Simon Mills director

Centre for Complementary Health Studies, University of Exeter, Exeter EX4 4RJ

Peter Fisher director of research

Royal London Homoeopathic Hospital, London WC1N 3HR

Jonathan Monckton director

Research Council for Complementary Medicine, London SW6 3JD

David Reilly director of academic departments Glasgow Homoeopathic Hospital, Glasgow G12 0NR

David Peters clinical director

Centre for Community Care and Primary Health, University of Westminster, London W1M 8JS

Kate Thomas deputy director

Medical Care Research Unit, University of Sheffield, Sheffield S1 4DA

1 Zollman C, Vickers A. What is complementary medicine? BMJ 1999;319:693-6. (11 September.)

2 Ernst E. Commitment to complementary medicine: politically correct lip service or co-ordinated strategy? J R Coll Phys Lond 1999;33:114-5.

3 Ernst E. Regulating complementary medicine. BMJ 1996:313:882.

4 Foundation for Integrated Medicine on behalf of the Steering Committee for the Prince of Wales Initiative on Integrated Medicine. Integrated healthcare. A way forward for the next five years? Discussion document. London: Foundation the next five years? Discussion doc

5 Eisenberg DM, Davis RB, Ettner SL, Appel S, Wilkey S, Van Eisenberg DM, Davis RB, Ettner SL, Appel S, Wilkey S, Van
Rompay M, et al. Trends in alternative medicine use in the Rompay M, et al. Trends in alternative medicine use in the
United States, 1990-1997. Results of a follow-up national survey. JAMA 1998;280:1569-75.

\section{Rapid responses} $e \mathrm{BM}$

Correspondence submitted electronically is available on our website www.bmj.com 